\title{
University
}

\author{
Tulane Economics Working Paper Series
}

\section{Testing Behavioral Public Economics Theories in the Laboratory}

\author{
James Alm \\ Department of Economics \\ Tulane University \\ New Orleans, LA \\ jalm@tulane.edu
}

Working Paper 1102

April 2011

\begin{abstract}
"Behavioral economics", or the application of methods and evidence from other social sciences to economics, has increased greatly in significance in the last two decades. An important method by which many of its predictions have been tested has been via laboratory experiments. In this paper I survey and assess experimental tests of various applications of behavioral economics to the specific area of public economics, or "behavioral public economics". I discuss the basic elements of behavioral economics, the methodology of experimental economics, applications of experimental methods to behavioral public economics, and topics in which future applications should prove useful.
\end{abstract}

Keywords: experimental methods, behavioral economics JEL: C9, H0, H3 


\title{
TESTING BEHAVIORAL PUBLIC ECONOMICS THEORIES IN THE $\angle A B O R A T O R Y$
}

\author{
James Alm
}

\begin{abstract}
"Behavioral economics", or the application of methods and evidence from other social sciences to economics, has increased greatly in significance in the last two decades. An important method by which many of its predictions have been tested has been via laboratory experiments. In this paper I survey and assess experimental tests of various applications of behavioral economics to the specific area of public economics, or "behavioral public economics". I discuss the basic elements of behavioral economics, the methodology of experimental economics, applications of experimental methods to behavioral public economics, and topics in which future applications should prove useful.
\end{abstract}

Key Words: Experimental methods, behavioral economics

JEL Codes: C9, HO, H3

James Alm: Department of Economics, Tulane University, 6823 St. Charles Avenue, 206 Tilton Hall, New Orleans, LA 70118 (phone 504862 8344; fax 504865 5869; email jalm@tulane.edu). 


\section{INTRODUCTION}

"Behavioral economics", loosely defined as the application of methods and evidence from other social sciences like psychology to economics, has increased enormously in significance in the last two decades, transforming the ways in which economists view the individual behavior. An important method by which its predictions and theories have been tested has been via laboratory experiments. In this paper I survey and assess experimental tests of various applications of behavioral economics to the specific area of public economics, or "behavioral public economics". I first discuss the basic elements of behavioral economics, as well as some criticisms of the approach. I then examine experimental tests of behavioral public economics using laboratory experiments, emphasizing the strengths and weaknesses of the experimental paradigm and the specific applications of experimental methods to behavioral public economics in three areas: public goods experiments, tax compliance experiments, and experiments on individual responses to taxes. I conclude by suggesting topics and areas in which future experimental tests of behavioral public economics should prove especially useful.

\section{A BRIEF “TUTORIAL"IN BEHAVIORAL ECONOMICS}

The standard neoclassical economic model of human behavior is based on several main assumptions: that individuals are rational, that they have unlimited willpower, and that they are purely self-interested. While these assumptions may be a useful starting point for the analysis of individual behavior, there is much accumulating evidence - often derived from laboratory experiments - that they are inaccurate and unrealistic depictions of many, perhaps most, individuals.

Indeed, there is growing acceptance that, contrary to the standard neoclassical approach: 
- individuals face limits on their ability to compute (e.g., "bounded rationality", "mental accounting")

- they systematically misperceive, or do not perceive at all, the true costs of actions (e.g., "fiscal illusion", "saliency", "overweighting" of probabilities)

- they face limits on their "self-control" (e.g., "hyperbolic discounting", "Christmas savings clubs", "automatic enrollment programs")

- they are affected by the ways in which choices are "framed" (e.g., reference points, gains versus losses, loss aversion, risk-seeking behavior)

- they are influenced by the social context in which, and the process by which, decisions are made, and

- they are motivated not simply by self-interest, but also by notions of fairness, altruism, reciprocity, trust, guilt, shame, morality, alienation, patriotism, social customs, social norms, and many other objectives.

In short, individuals are not always the rational, outcome-oriented, self-controlled, selfish, and egoistic consumers envisioned by much of our standard theory.

Behavioral economics uses these so-called "departures" from the standard assumptions as the starting point for a more realistic view on how individuals actually make choices. As discussed in detail by Camerer and Lowenstein (2004), McCaffery and Slemrod (2006), Wilkinson (2007), and Angner and Loewenstein (2010), among others, "behavioral economics" can be broadly defined as an approach that uses methods and evidence from other social sciences (especially psychology) to inform the analysis of individual and group decision making. ${ }^{1}$

The emergence of behavioral economics is sometimes viewed as a recent phenomenon. However, the relevance of behavioral insights has long been part of economics, including the works of many of the most prominent economists, from Adam Smith's The Theory of Moral Sentiments, to Francis Edgeworth's Theory of Mathematical Psychics, to Irving Fisher's The Money IIIusion, and to John Maynard Keynes' The General Theory. Even in the last fifty years, economists like Herbert Simon (Administrative Behavior), George Katona (Psychological Analysis of Economic Behavior), and Tibor Scitovsky (The Joyless Economy: The Psychology of

\footnotetext{
${ }^{1}$ For more "popular" discussions, see Ariely (2008) and Thaler and Sunstein (2008).
} 
Human Satisfaction) have incorporated, indeed emphasized, the importance of psychology in individual decision-making. In this light, the origin of the name "behavioral economics" is somewhat obscure. One of the first uses was by Boulding (1958), who wrote that there will be movement toward "behavioral economics", which “...involves study of those aspects of men's images, or cognitive and affective structures that are more relevant to economic decisions". Given the essential role of psychological insights in the field, together with the obvious truism that all economics concerns "behavior" in one form or another, a more descriptive name for the field is perhaps "cognitive economics", as recognized early on by Boulding (1958).

The use of behavioral methods is not without some criticisms. A common one is that there is no single unified "theory" of individual behavior that applies across the various individual behaviors. Indeed, a "typical" behavioral economics paper often starts with some anomaly that standard theory cannot easily explain, proceeds to a specific model of the bias, and then concludes with an experimental demonstration of the "correct" explanation. Such an approach clearly lacks the generality that is commonly associated with the neoclassical paradigm. However, progress is clearly being made in modeling individual behavior. ${ }^{2}$ Further, as I argue in the concluding section, I believe that it is futile to believe that one single model or modeling approach can hope to explain the diversity of human behavior.

A second criticism of behavioral economics is that the focus is often on individua/behavior (as well as on tests of the underlying assumptions of individual behavior), rather than on the broader dimension of aggregate, group, or market behavior. Closely related to this criticism is a third one: although individuals may not always behave "rationally", individual bias may well "wash out" in the aggregate, and it is aggregate behavior that is most relevant for economics. As

2 Many modeling approaches have as their starting point "prospect theory" (Kahneman and Tversky, 1979), but much recent work incorporates many other approaches. See Camerer and Lowenstein (2004), McCaffery and Slemrod (2006), Wilkinson (2007), and Angner and Loewenstein (2010) for detailed discussions. 
noted by Glaeser (2004), "[t]he great achievement of economics is understanding aggregation... Our discipline has always been about the wealth of nations, not individuals". Indeed, Becker (1962) demonstrated long ago that, as long as some individuals in a market respond predictably to incentives, markets will perform as predicted; that is, individual anomalies are less important than aggregate rationality. This criticism is certainly an apt one. Even so, markets are the aggregation of individuals, so that a better understanding of individual behavior must necessarily help in understanding market behavior. Also, to claim that behavioral economists do not consider the aggregate implications of behavioral issues is simply untrue, as shown by the work of Chetty, Looney, and Kroft (2009) on tax salience, among many others. Perhaps most controversial in behavioral economics is the paternalistic implications of many behavioral insights. If individuals have a limited ability to compute, if they do not perceive the true costs of actions, if they face limits on their self-control, if they are affected by the ways in which choices are framed, if they are influenced by the social context in which (and the process by which) decisions are made, and if they are weakly motivated, then giving them more options in choosing, say, where to invest their retirement savings may not make them better off. Instead, some circumscribed choices (e.g., a "default" investment option in savings plans) may make them better off. This is the underlying motivation for the "soft paternalism" notions that are most fully articulated in Thaler and Sunstein (2008).

However, to many critics, moving forward with these paternalistic policy proposals is premature and unjustified. They argue (again) that, although individuals may often make poor choices, aggregate rationality cancels out individual psychology. Glaeser (2006) also argues that individual irrationality is not limited to individuals who make choices in markets but extends to individuals in all dimensions of their behavior, including those who make choices about 
government policy; because individuals have a greater incentive to choose wisely in market settings than in government settings, he concludes that behavioral economics actually strengthens the case for limited government.

Still, I believe that it is hard to avoid the conclusion that economists make normative judgments about "good" policy all the time. What behavioral economics emphasizes is that it is precisely because human decisions are so sensitive to the context in which they are framed that we need to recognize more fully the role that our underlying cognitive processes settings play in our decisions. As David Foster Wallace said in his 2005 commencement speech at Kenyon College, all of us are a slave to what he termed our "natural hard-wired default-setting, ... which is to be deeply and literally self-centered and to see and interpret everything through this lens of self". He further argues that we need to work hard - and we need help - in getting free of this default-setting. It is especially in this sense that behavioral economics, with its soft paternalism, may be able to help individuals in making decisions that, even from their own perspective, make them better off.

\section{THE METHODOLOGY OF EXPERIMENTAL ECONOMICS}

Many tests of behavioral economics theories have taken place via laboratory experiments. The use of laboratory experiments in economics began in earnest in the early 1960s with work on resource allocation under alternative forms of market organization. Growth in its applications came with the establishment of a well-defined framework for experimental work by Smith (1976, 1982), and laboratory methods are now widely accepted as a methodological approach in the analysis of theory and policy, especially of behavioral economics. ${ }^{3}$

\section{A. Experimental Economics as "Induced Value Theory"}

\footnotetext{
${ }^{3}$ For comprehensive surveys of experimental methods, see Davis and Holt (1993) and Kagel and Roth (1995).
} 
Experimental economics involves the creation of a real microeconomic system in the laboratory, one that parallels the naturally occurring world that is the subject of investigation and one in which subjects (usually students) make decisions that yield individual financial payoffs whose magnitude depends on their decisions. The essence of such a system is control over the environment, the institutions, the incentives, and the preferences that subjects face. Of these, control over preferences is particularly crucial. As emphasized by Smith (1976), "[s]uch control can be achieved by using a reward structure to induce prescribed monetary value on actions." Smith (1982) identifies a set of sufficient conditions for control over preferences to be established:

- Nonsatiation: Subjects prefer more to less of the reward medium.

- Saliency: The rewards received by subjects are related to their decisions, so that subjects recognize that their actions affect their outcomes.

- Reward Dominance: The rewards are large enough to offset any subjective costs or benefits that subjects place on participation in the experiment.

- Privacy: each subject knows only his or her own payoffs, so that they do not receive any subjective value from the payoffs of other subjects.

Nearly all recent experimental studies invoke these conditions. ${ }^{5}$

Several other procedures should also be followed in experiment. The experiment should be administered in a uniform and consistent manner to allow replicability. The experiment should not be excessively long or complicated, since subjects may become bored or confused. Subjects must believe that the procedures described to them are the procedures actually followed. The instructions provided to subjects should be understandable, should avoid the use of examples that lead subjects to anchor on certain choices that are the focus of the experiment, and should be

\footnotetext{
${ }^{4}$ Smith (1976) goes on to write that a maintained assumption in experimental economics is the following: "[g]iven a costless choice between two alternatives, identical except that the first yields more of the reward medium... than the second, the first will always be chosen (preferred) over the second". It is in this sense that Smith (1976) refers to experimental economics as "induced value theory".

5 There are, however, some exceptions to these conditions. For example, one does not want to impose Privacy in an experiment on, say altruism because the payoffs to others are an essential part of the research issue.
} 
phrased in "neutral" rather than "loaded" terms, in order to mask the context of the experiment and to avoid direct reference to the real-world phenomena under investigation. ${ }^{67}$

\section{B. Why Use Experimental Methods?}

On some level, the use of experimental methods derives from a fundamental problem with economics. Like other sciences, economics is based on the development of theory and on the ability of that theory to explain observed activities. However, unlike some other sciences, especially the natural sciences, economics faces substantial difficulties in empirically testing the predictive power of its theories using data from the naturally occurring world. Given the dizzying array and complexity of forces that operate in market (and non-market) systems, economists can never be quite certain that they are "holding constant" the many factors that may be driving individual choices, so that they can focus on the "true" driving factors that are the object of empirical testing. Methods for achieving such identification have become increasingly sophisticated over time, especially with the use of so-called "natural experiments" and "controlled field experiments". Even so, there are few instances in which such identification is uncontroversial (Leamer, 1983).

There are of course numerous avenues for testing the predictions of behavioral economics, aside from experimental methods, including the use of hypothetical choices, natural experiments, controlled field experiments, and even process measures like magnetic resonance imaging. Of special note are the increasing examples of empirically based tests of behavioral economics, as demonstrated by tests of tax salience (Chetty, Looney, and Kroft, 2009;

\footnotetext{
${ }^{6}$ Neutrality increases the experimenter's control over subject preferences, and avoids leading subjects to invoke different "mental scripts", which may enable them to fill in (potentially) missing information in the instructions but which also may unpredictably influence their choices. It is sometimes claimed that the use of neutral instructions limits the ability to generalize from the experimental to the naturally occurring setting. In fact, however, as argued by most experimental economists, it is not possible to generalize beyond the laboratory unless one uses neutral instructions, since the experimenter cannot control (or induce) the values that subjects associate with loaded terms. ${ }^{7}$ See Davis and Holt (1993) for examples of instructions for a variety of experiments.
} 
Finkelstein, 2009), of savings programs (Laibson, Repetto, and Tobacman, 1998; Madrian and Shea, 2001; Thaler and Benartzi, 2004; Bayer, Bernheim, and Scholz, 2009), of the design of health insurance plans (Kling et al. 2009; Abaluck and Gruber, 2009), and of financial assistance in college applications (Dynarski and Scott-Clayton, 2006; Bettinger et al. 2009). ${ }^{8}$ Even so, experimental methods have often been a common approach, and economists have increasingly begun to emulate the methods of natural scientists by conducting carefully controlled laboratory experiments.

Economics generally and public economics specifically have profited from the use of laboratory experiments, for several reasons. Econometric data on research questions obtained from the naturally occurring world can be unreliable, can fail to show the variation or distinctions of interest, or can fail to provide sufficient identification to discern "cause and effect". Indeed, in some cases data simply cannot be assembled outside the laboratory because the real world setting of relevance does not exist. For its part, theoretical analyses often cannot incorporate fully, appropriately, or tractably many relevant factors.

What can experiments do? Unlike standard theoretical work, experiments are not as constrained by the same degree of simplification required in analytical studies, which allows the impact of numerous factors not amenable to theoretical work to be examined precisely and unambiguously in a controlled environment. Unlike traditional empirical work based on naturally occurring data, experiments generate data under settings in which there is control over extraneous influences. Laboratory experiments also provide a controlled environment that allows one to examine the mechanisms of interest, as well as the changes in these environments and institutions, in isolation from each other.

\footnotetext{
${ }^{8}$ See DellaVigna (2009) for a survey of many field studies of behavioral economics.
} 
As I discuss later, there are some obvious limitations of experimental methods. However, given the limitations of theoretical and econometric work, there are, I believe, compelling reasons for the use of experiments, as an additiona/ (and not as the only) methodological tool, in large part because laboratory experiments give a researcher the twin advantages of control (including data generation and replicability from this control) and flexibility.

First, laboratory methods allow the investigator to control the institutions and incentives facing subjects in order to investigate the main issue of interest. Relatedly and importantly, laboratory methods allow the investigator to generate data on individual and group choices in settings where these institutions and incentives can by varied singly and independently in order to examine responses to separate changes in these factors. In the naturally occurring world, such control is seldom if ever available. Data on, say, individual tax compliance decisions may not exist or, even if available, are likely to be imprecise, incomplete, and unreliable. Further, data on the responses of individuals to the myriad factors thought to influence the compliance decision may confound these many influences, making it difficult to disentangle their effects on compliance. Finally, it is likely that independent variation in many of these influences is simply not possible in the naturally occurring world, making it impossible to measure their effects on individual and group behavior. Laboratory methods allow such data to be generated in a setting in which each relevant factor can be separately manipulated and outcomes of subject choices reliably observed. They also allow other investigators to replicate more-or-less identical laboratory settings in order to determine whether the results are robust, an essential attribute of any science.

Second, laboratory methods give the investigator substantial flexibility in examining the effects of supposedly relevant considerations on individual and group decisions. It is difficult to 
imagine real-world settings in which, say, notions of fairness, altruism, and trust can be manipulated in a reliable manner. Carefully designed experiments give the investigator precisely this flexibility, thereby allowing theories based on these notions (and the assumptions of these theories) to be tested in a controlled environment.

\section{Some Limitations of Experimental Methods}

Despite the demonstrated usefulness of experimental methods, there are sound reasons for caution in interpreting and generalizing experimental results. Some early experiments did not follow some now widely accepted procedures of the experimental paradigm, such as the use of repeated decisions and of neutral instructions. Much early work also lacked realism because values of the various policy parameters did not approximate real-world values.

Although more recent experimental research has generally addressed these problems, some concerns remain, some of which are more legitimate than others.

A common criticism of experimental economics is that the student subjects typically used may not be representative of taxpayers. However, there is now much evidence that the experimental responses of students are seldom different than the responses of other subject pools (Plott, 1987). In a more fundamental sense, there is no reason to believe that the cognitive processes of students are different from those of "real" people, which suggests that the burden must be on skeptics to prove that these processes actually do differ.

Another common criticism is that it is not possible to control for many relevant factors in the laboratory. However, if one cannot control for such factors in the laboratory where the experimenter establishes the institutions, the rules, and the reward structure, then one cannot hope to control for these factors in the naturally occurring world. 
Of more legitimate concern, the results may well be sensitive to the specific experimental design. Indeed, a laboratory experiment is only as good as its design: if the institutions and environments imposed in the lab do not parallel systems of interest in the world, the resulting experimental data can be useless or misleading. Replication is therefore crucial.

It is also possible that subjects may modify their behavior simply because they know that they are participating in an experiment, exhibiting more "obedience to authority" and more "prosocial behavior" in the laboratory than in the naturally occurring world (Levitt and List, 2007). Most critically, there is a certain artificiality in any laboratory setting. A decision to report, say, three tokens of income in a tax compliance experiment is clearly different from a decision to report actual income on an annual tax return, even if the laboratory incentives are salient. In particular, the laboratory setting cannot capture certain types of incentives (e.g., a catastrophic loss such as jail), and it cannot capture the social stigma that some surveys suggest is an important factor in taxpayer reporting.

The crucial issue in experimental methods is therefore the "external validity" of laboratory methods; that is, do the results in the laboratory apply more broadly to the "naturally occurring world"? This is an issue that cannot be answered in general for all experimental studies, but must be addressed in each specific case. (It is also an issue that controlled field experiments must address. ${ }^{9}$ ) For example, in the specific case of tax compliance experiments, there is now emerging evidence that the results found in the laboratory do in fact achieve such external validity. Alm, Bloomquist, and McKee (2010) present several types of evidence that relates directly to the use of student subjects. Preliminary examination of these data indicate that the experimental responses of students are seldom different than the experimental responses of

\footnotetext{
${ }^{9}$ For example, field experiments do not fully control subject valuations of commodities used in the field, they cannot generalize beyond the specific subject pool that is investigated, and they face significant difficulties in conducting replications.
} 
other subject pools, and that experimental data versus Internal Revenue Service data also indicate similar patterns. These results are consistent with many other experimental studies that demonstrate that student and non-student subjects behave and respond similarly.

In short, one must use the results from laboratory experiments with some care. However, such use depends largely upon the purpose of the experiment. According to Roth (1987), experiments can be classified into three broad categories that depend upon the dialogue in which they are meant to participate. "Speaking to Theorists" includes those experiments designed to test well-articulated theories. "Searching for Facts" involves experiments that examine the effects of variables about which existing theory has little to say. "Whispering in the Ears of Princes" identifies those experiments motivated by specific policy issues. To date, most experiments in behavioral public economics have fallen into the first two categories. However, this is now changing, and experiments are being increasingly used to illuminate public policy.

\section{SOME APPLICATIONS TO BEHAVIORAL PUBLIC ECONOMICS}

In this section, I discuss some of the areas in behavioral public economics that have employed laboratory experiments. My discussion here is necessarily brief, and focuses on only three of the many areas in which experimental methods have been applied to behavioral public economics. For a more detailed discussion of experimental methods, which also considers nonbehavioral applications, see Alm and Jacobson (2007).
A. Public Goods ${ }^{10}$

\footnotetext{
10 Note that there is also relevant experimental work on voting and voting processes. See Palfrey (2006) for a survey of work that has been done with laboratory experiments in political science, classified in four main categories: committee decision making, elections and candidate competition, information aggregation and committees, and voter turnout and participation games.
} 
The standard theory of public goods concludes that the Nash equilibrium is characterized by zero voluntary contributions to public goods, as individuals attempt to "free ride" on the contributions of others. However, there are numerous examples from the naturally occurring world in which many individuals contribute positive amounts to public goods (e.g., public radio, volunteer work, and charitable donations). Experiments have been employed both to determine the circumstances under which individuals will contribute and to determine mechanisms that will help overcome the free rider problem.

A typical "voluntary contributions" experiment begins by assigning student subjects to groups. Subjects are endowed with tokens and are isolated from each other. Each subject is offered two possible "investments", one in a private good and one in a public good. The private good investment has higher returns for that individual, but the public good investment provides a return to all members of the group; that is, the public good investment is both nonrival (because all members of the group derive the same benefit from any member's contribution) and nonexclusive (because subjects who do not contribute to the public good investment still receive the same group return). Subjects are then asked to choose an allocation of tokens between the investments. Because the total social return is greater for the public good than for the private good, the socially efficient outcome is for everyone to contribute fully to the public good. However, as with the standard prisoner's dilemma game, each individual has an incentive to keep all of his or her tokens because the private good investment has a higher personal return than the public good investment. This contribution game is then repeated for a number of rounds, and the level of actual contributions is compared to the Nash equilibrium prediction (zero contributions) and the socially efficient outcome (full contributions). 
There are numerous variants on this basic design. While early work focused on "oneshot" games, the standard approach in recent work has been to examine subject responses over multiple rounds. The public good return is often linear with respect to the contributions, but it can be based on a "threshold" (or a "provision point") in which the group return will only be provided if total contributions exceed some designated threshold; relatedly, "incentive compatible" mechanisms have been examined. The return on the group investment can be varied. Subjects with different levels of experience in the contribution experiments can be examined. Similarly, subjects can remain in the same group for the entire experiment, or the assignment of subjects can be randomly varied from round to round. Group size can also vary, from "small" to "large" groups, and the subject "type" can also change in order to examine whether, say, men behave differently than women or economics students behave differently than other students. In most experiments, privacy is maintained, in the sense that individual subjects' contribution choices are not revealed to other subjects, subjects are not allowed to communicate with one another, and subjects do not know anything about other members of the group. However, others' choices can be revealed, group communication can be allowed via "cheap talk", and individual identities can be shown to all subjects. Alternately, privacy can be further enhanced by using a "double blind" procedure to shield the identity of the subjects' contributions, not only from other subjects but also from the experimenter, so that data on each subject's contributions cannot be linked to the specific subject's identity by anyone.

All of these experiments aim to answer the core questions of public goods provision. How much are people willing to contribute to a public good? Of particular relevance to behavioral public economics, why do they contribute at all? Also, what institutional and environmental factors can increase contributions? It is noteworthy that many recent studies have 
introduced new theories based upon behavioral economics. These models introduce such factors as: altruism (Becker, 1974; Andreoni and Miller, 2002; Cox and Sadiraj, 2007), impure and warm-glow altruism (Andreoni, 1989, 1990), inequality aversion (Fehr and Schmidt, 1999; Bolton and Ockenfels, 2000), confusion versus altruism (Andreoni, 1995), and reciprocity (Sugden, 1984).

In a survey of voluntary contributions experiments, Ledyard (1995) concluded that the results from the varied experiments are often contradictory. Even so, he suggested a range of somewhat different "stylized facts" arising out of all of this work. The stylized facts that are most relevant to behavioral public economics can be summarized as:

- Many subjects contribute to a public good, sometimes in significant amounts.

- There is substantial individual variation in contributions, suggesting that individuals are motivated by different considerations.

- At least at the outset, subjects contribute halfway between the socially efficient level and the free riding level.

- Contributions decline with repetition but eventually stabilize.

- Individuals change their contributions in ways influenced by the experimental structure. For example, subjects tend to contribute at a higher rate if there is face-to-face communication (e.g., "cheap talk"), a larger group size, a higher marginal return on the group investment, or a larger individual endowment.

\section{B. Tax Compliance ${ }^{11}$}

Applying the standard economics-of-crime model of compliance of Allingham and Sandmo (1972) in the laboratory is straightforward, and, beginning with the seminal experimental study of Friedland, Maital, and Rutenberg (1978), the basic design of most compliance experiments has been similar. Human subjects in a controlled laboratory are told that they should feel free to make as much income as possible. At the beginning of each round of the experiment, each subject is given income and must decide how much income to report.

\footnotetext{
${ }^{11}$ See Torgler (2002) for a survey of experimental analyses of tax compliance. Also, see Andreoni, Erard, and
} Feinstein (1998) and Slemrod and Yitzhaki (2002) for surveys of the broader compliance literature. 
Taxes are paid at some rate on all reported, but not on underreported, income. However, underreporting is discovered with some probability, and the subject must then pay a fine on unpaid taxes. This process is repeated for a given number of rounds. At the completion of the experiment, each subject is paid an amount (the accumulated earnings) that depends on his or her performance during the experiment. Various policy changes can easily be introduced, such as changes in audit probabilities or audit rules, in penalty rates, in tax rates, in public good provision, in institutions that affect tax equity or social norms, and in many other relevant policies or institutions.

The main fiscal variables of interest in the compliance decision are audit, penalty, and tax rates, and these factors have been extensively examined. Nearly all experimental studies have found that a higher audit rate (i.e., a greater probability of audit) leads to more compliance, with an estimated reported income-audit rate elasticity that varies within the narrow range of 0.1 to 0.2 , although this impact appears to be nonlinear, there is also evidence that many subjects appear to substantially overweight the probability of an audit, so that there is far more compliance than is predicted by expected utility theory. Most studies have also found that compliance increases but only slightly with increases in the fine rate on unpaid, and that a higher marginal tax rate often (although not always) leads to less compliance. ${ }^{12}$

Of more relevance to behavioral economics, many behavioral factors have also been investigated, especially in recent work based on behavioral theories (Yaniv, 1999; Bernasconi and Zanardi, 2004; Dhami and al-Nowaihi, 2007).

\footnotetext{
12 There are also experiments that link the voluntary contributions and the compliance literatures, by allowing for a public good financed by voluntary tax payments, experiments that examine demographic factors (e.g., sex, age), and experiments that analyze alternative audit selection mechanisms. See Torgler (2002) Alm and Jacobson (2007) for a detailed discussion of these studies.
} 
An especially important behavioral factor in many compliance studies is the role of social institutions and social processes, including the notion of a "social norm". Elster (1989) defines a social norm as a pattern of behavior that is judged in a similar way by others and that therefore is sustained in part by social approval or disapproval. Consequently, if others behave according to the socially accepted mode of behavior, then the individual will behave appropriately; if others do not so behave, then the individual will respond in kind. A social norm is therefore largely process-oriented, unlike the outcome-orientation of the neoclassical view of individual behavior. In the context of tax compliance, the existence of a social norm suggests that an individual will comply as long as he or she believes that compliance is the social norm; if noncompliance becomes pervasive, then the social norm of compliance disappears. There are other concepts that describe the same basic phenomenon as social norms, such as "psychic costs" (Gordon, 1989), "moral sentiments" (Erard and Feinstein, 1994), "tax morale" (Pommerehne, Hart, and Frey, 1994), "group conformity and social customs" (Myles and Naylor, 1996), and "intrinsic motivation" (Frey, 1992).

In this regard, Alm, Jackson, and McKee (1993) demonstrated that government can increase this social norm (and thereby improve compliance) by ensuring that individuals have a say in the decision process by voting on the specific way in which their taxes are to be used and by spending taxes in ways consistent with citizen preferences; that is, subjects pay more in taxes when they choose the use of their taxes by voting than when the identical use is imposed upon them, compliance is greater when the vote is decisive than when the vote is close, and compliance is significantly and dramatically lowered by the imposition of an unpopular program. Similarly, Alm, McClelland, and Schulze (1999) showed that the social norm fell, often collapsing virtually to zero, when there was a social expression via group selection of the fiscal 
regime of a willingness to tolerate tax evasion, such as a majority vote in favor of reduced enforcement on detected evasion; however, they also found that the norm can be improved (and compliance can be increased) when there was a social expression of an unwillingness to tolerate tax evasion. Torgler (2003) and Gërxhani and Schram (2006) also found experimental evidence that that the social norm can be affected by the institutions that face individuals, by individuals' attitudes toward these institutions, and by individual participation in the selection of those institutions.

Other experiments have also demonstrated the role of social norms in compliance. For example, Webley et al. (1991) found that individuals who have a negative attitude toward government comply less as a result. Alm, Sanchez, and de Juan (1995) found significant differences in the compliance behavior of student subjects in similar experiments but in different countries (Spain versus the United States), thereby suggesting that societal attitudes toward compliance exert a measurable impact on tax compliance.

In other work on institutions and processes, Spicer and Thomas (1982), Friedland (1982), Beck, Davis, and Jung (1991), and Alm, Jackson, and McKee (1992) found that institutional uncertainty about tax, penalty, and audit rates can affect compliance, although with sometimes offsetting effects. In earlier work, Spicer and Becker (1980) conducted experiments that suggested that perceptions of "fiscal inequity" affect compliance: compliance was lower (higher) among subjects who were told that their tax rate was higher (lower) than that of others.

Some "stylized facts" that emerge from this work on compliance, especially related to behavioral issues, include:

- Audit rates affect compliance - More audits increase compliance but in a non-linear way, so that the deterrent effect diminishes with higher audit rates. Further, audits have a "spillover" effect, or an increase in compliance independent of revenues generated 
directly from the audits themselves, and audits have a greater deterrent effect than fines, despite their theoretical equivalence (at least in an expected value sense),

- Perceptions of audit rates affect compliance - Individuals appear to substantially overweight a (low) probability of audit.

- Tax rates affect compliance - The level of tax rates matters, but one's tax rate relative to others' (e.g., perceptions of fiscal inequity) also is relevant. Further, the use of taxes affects compliance, especially when subjects can choose these uses.

- Process (versus outcome) affects compliance - Social norms can be affected by the institutions that face individuals, by individuals' attitudes toward these institutions, and by individual participation in the selection of those institutions.

- Simplicity versus complexity affects compliance, but in ways that remain unresolved.

More broadly, compliance is driven by far more than the purely financial considerations of detection and punishment, but in ways that are not yet fully understood.

\section{Behavioral Responses to Taxes}

Taxes can cause real behavioral changes by pushing taxpayers into evasion activities, as discussed earlier, and into other types of decisions; that is, the return on the taxed activity is reduced because of the tax, and people should tend to participate less in the taxed activity. Aside from tax compliance behavior, the type of response that has been most studied is some aspect of labor supply response. In these experiments, subjects are provided with a work task (e.g., typing numbers into a computer) and a leisure task (e.g., playing a game). During short work periods, they work, and they are paid by the productivity of their work (e.g., the number of keystrokes typed). They may be able to choose the length or frequency of breaks from work, in which they perform the unpaid leisure task. Over subsequent periods, different taxes are imposed on the return from the work task. Work effort or time worked can then be studied.

Swenson (1988) first conducted these work behavior experiments. His experimental results supported the existence of a Laffer curve in that work effort decreased with increases in the tax rate beyond some level. Sillamaa (1999a, 1999b) also examined this issue; however, in her design subjects were paired and the tax rate was endogenously determined by the worker's 
partner. She found that a zero marginal tax rate increased work effort and that work effort was higher under a linear than a nonlinear tax schedule. ${ }^{13}$ Other work on labor supply responses includes Blumkin, Ruffle, and Ganun (2008), who found that subjects responded differently to an income tax than to an equivalent consumption tax. Similarly, Sausgruber and Tyran (2005) examined differential subject responses to taxes that, at least in theory, are equivalent (e.g., direct versus indirect taxes), and found differential responses, despite the predictions of theory.

Other papers examining real responses to taxes have taken varied approaches. For example, de Bartolome (1995) investigated whether people respond to average or marginal tax rates. He showed tax schedules to students, and asked them to choose between an untaxed (but lower return) and a taxed (and higher return) savings vehicle, as returns were varied. His experimental results suggested that many subjects appeared to base their decision on the average tax rate. Baron and McCaffery (2003) also showed that individuals may not accurately perceive the relevant tax burden; that is, they tended to underestimate the total tax burden when the burden was distributed across many smaller taxes.

\section{CONCLUSIONS: SOME FUTURE DIRECTIONS}

It is, I hope, apparent that laboratory experiments on behavioral public economics have considerably expanded our knowledge of many dimensions of the field. We now know much more about why people contribute to public goods, about why they pay their taxes, and about how individuals respond to tax incentives. Indeed, to date the main purpose of behavioral economics has been to understand how people make decisions, and the main purpose of experimental work on behavioral public economics has similarly focused on examining

\footnotetext{
${ }^{13}$ For other Laffer curve experiments, see Sutter and Weck-Hannemann (2003) and Lévy-Garboua, Masclet, and Montmarquette (2005).
} 
individual decisions. Accordingly, I conclude by discussing several areas in behavioral public economics to which the future application of laboratory methods seems especially valuable. These areas fall into three main categories: testing new areas (and developing new theories) of individual responses to taxes; moving beyond individual decisions to the aggregation - and the evolution over time - of individual decisions to group behavior; and incorporating other social sciences (e.g., sociology, anthropology) in order to understand better which features of naturally occurring settings are likely to affect individual and group decisions.

In the first area - testing new areas (and developing new theories) of individual responses to taxes - there is much scope for experimental work. Focusing only on tax compliance, I believe that experimental methods could be usefully applied to such behavioral issues as:

- How does the presence of taxpayer uncertainty about one's "true" taxable income (or other aspects of the tax system) affect compliance?

- Does tax simplification contribute to more - or less - tax compliance? Put differently, is compliance greater or lower in a simpler versus a complex tax system, and can better tax agency services improve taxpayer compliance?

- Can positive inducements to the group (e.g., public goods, social insurance programs) and/or to the individual (e.g., lotteries) improve compliance?

- Can individuals "coordinate" their compliance decisions, perhaps via communication?

- How is information about enforcement disseminated among taxpayers, and how do taxpayers respond to this information?

- Can social norms be deliberately and predictably affected by government policies?

- How do perceptions of "fiscal inequity" affect compliance?

- Under what circumstances does greater enforcement increase compliance, and when does it instead lead down a "slippery slope" that destroys "trust" and crowds out "intrinsic motivation"?

- Does public disclosure of audit results act as a non-financial deterrent?

- Is compliance affected by the "cost" - financial or emotional - of an audit?

Of these issues, I believe that the most important is whether and how compliance is affected by societal institutions and social processes (including individual choice of these institutions and processes). For example, how is compliance affected by the use of tax revenues and the ways in which this use is determined? There is already some experimental work on some of these issues. 
For example, Alm and McKee (2004) examine the coordination aspect of compliance, Kirchler, Hoelzl, and Wahl (2008), in their "slippery slope" framework, examine when psychological factors work/fail, and Alm, Cherry, Jones, and McKee (2010) examine the effects of complexity and of government services that reduce this complexity on tax compliance. Even so, much additional work is required.

Similarly, in other areas of individual taxpayer responses to taxes, there are many dimensions of behavior that can be usefully examined in the laboratory but that so far remain largely unexplored. Do individuals respond differently:

- To a tax credit versus an equivalent tax deduction?

- To a tax discount from a "high" tax base versus an equivalent tax surcharge from a "low" tax base?

- To a tax change framed as a percentage change versus as an absolute (dollar) change?

- To a tax change defined in terms of their own tax liability only versus an equivalent tax change that compares their change to that of others?

- To the timing of a tax change (e.g., one "large" change versus many equivalent "small" tax changes)?

- To an ongoing (e.g., monthly) tax withholding versus an equivalent one-time payment?

- To savings programs that have "commitment" or "heuristic" devices (e.g., forced payroll savings plans) versus programs with only "traditional" financial incentives?

The basic issue here is how individuals are affected in their tax-related decisions by such behavioral notions as saliency, mental accounting, and context.

More broadly, there are many other dimensions of individual choices that are relevant to experimental tests of behavioral public economics:

- Intertemporal decisions - The effect of taxation on saving decisions has yet to be thoroughly examined in a laboratory setting (aside from some experiments on Ricardian equivalence), despite the fact that experiments seem ideally situated to examine individual choices over multiple periods. Work on hyperbolic discounting, self-control, and mental accounting is clearly relevant here.

- Social insurance programs - Even though individual behavior in uncertain environments has been extensively studied in the laboratory, the broader behavioral implications of government-provided social insurance have been almost completely neglected. Linking the public good aspects of social insurance programs with their uncertainty effects seems an especially promising area of research. 
- Behavior under uncertainty - Most all theoretical analyses of taxpayer behavior under uncertainty has utilized expected utility, despite its well-known shortcomings. It is essential that other approaches that are based upon behavioral economics be applied and tested in the laboratory. As noted above, applications to social insurance programs are clearly relevant here.

These are all issues for which the standard neoclassical paradigm gives clear-cut theoretical answers. However, these "answers" are often misleading or wrong. Testing behavioral public economics notions in the laboratory presents the possibility of demonstrating behavioral responses that are more accurate and realistic, that show the relevance of social context and social process in decisions, and that have the "external validity" necessary for policy formulation. In this regard, these behaviors need to be formally modeled. The work of Chetty, Looney, and Kroft (2009) clearly demonstrates that it is possible to use these types of results to develop new theories of individual behavior that are based firmly on behavioral public economics notions. In these modeling efforts, it is also essential to recognize that one theory may not fit all individuals at all times, or even the same individual at different times. There is great diversity in individual behavior, and as argued by Gould (1996) in a different context (e.g., evolution), it is grossly misleading to represent a complex system by a single, so-called representative agent, who behaves in some average or typical way. Instead, most systems have incredible variety - a "full house" of behaviors, in the words of Gould (1996) - and the proper understanding of any system requires recognition of this basic fact.

The second area involves moving beyond individual decisions to the aggregation - and the evolution over time - of individual decisions to group behavior. ${ }^{14}$ Ultimately, public policy considerations require that we be interested in understanding and explaining group behavior.

\footnotetext{
${ }^{14}$ There is in fact some experimental work on aggregate or market behavior, including experimental tests of tax incidence in competitive and in imperfectly competitive markets and tests of tax equivalence propositions. For example, see Kachelmeier, Limberg, and Schadewald (1994, Quirmbach, Swenson, and Vines (1996), Borck et al. (2002), Kerschbamer and Kirchsteiger (2000), and Ruffle (2005), and Riedl and von Winden (2007).
} 
Behavioral public economics, especially in its experimental tests, allows us to understand better which features of naturally occurring settings are likely to affect individual and group decisions. For example, Bloomquist (2010) uses "agent-based modeling" approach, calibrating the model to observations from laboratory experiments, in order to simulate evolutionary changes in compliance. He finds that the initial number of "honest" business owners declines quickly and significantly, being displaced by proprietors having either "defiant" or "strategic" compliance behaviors. This approach, combining experiments with simulations, seems an especially fruitful area for future research.

A third area for future research in public behavioral economics involves incorporating the insights from other social science like sociology and anthropology, in order to understand better which features of naturally occurring settings are likely to affect individual and group decisions. For example, the notion of "reciprocity" arises in large part from anthropology, and that of "adherence to group norms" from sociology. Using these alternative perspectives to human behavior cannot help but expand our understanding of individual behavior, as demonstrated most clearly in Akerlof and Kranton (2000), Akerlof (2002), and Akerlof and Shiller (2009).

In short, I believe that the future prospects for the application of experimental methods to behavioral public economics are exciting and unlimited. The challenge here is to design experiments that parallel the essential elements of the naturally occurring world that are of interest, so that the experiments can demonstrate the external validity necessary to inform policy. Such experiments have enormous potential to add further to our understanding of how government policies affect the "full house" of individual decisions, and to help in our devising government policies that address this "full house" of behaviors in devising its policies.

\section{ACKNOWLEDGEMENTS}


I am grateful to Alan Auerbach, Brian Erard, Joel Slemrod, and other participants at the May 2010 National Tax Association Spring Symposium in Washington, D.C. for helpful comments.

\section{REFERENCES}

Abaluck, Jason T. and Jonathan Gruber, 2009. "Choice Inconsistencies among the Elderly: Evidence from Plan Choice in the Medicare Part D. Program." NBER Working Paper 14759, National Bureau of Economic Research, Cambridge, MA.

Akerlof, George A., 2002. "Behavioral Macroeconomics and Macroeconomic Behavior." The American Economic Review 92 (3), 411-433.

Akerlof, George A. and Rachel E. Kranton, 2000. "Economics and Identity." The Quarterly Journal of Economics 115 (3), 715-753.

Akerlof, George A. and Robert J. Shiller, 2009. Animal Spirits: How Human Psychology Drives the Economy and Why It Matters. Princeton University Press, Princeton, NJ.

Allingham, Michael G. and Agnar Sandmo, 1972. "Income Tax Evasion: A Theoretical Analysis." Journal of Public Economics 1 (3-4), 323-338.

Alm, James, Kim Bloomquist, and Michael McKee, 2010. "On the External Validity of Tax Compliance Experiments." Andrew Young School of Policy Studies Working Paper, Georgia State University, Atlanta, GA.

Alm, James, Todd Cherry, Michael Jones, and Michael McKee, 2010. “Tax Information Assistance Services and Tax Compliance Behavior." Journal of Economic Psychology forthcoming.

Alm, James, Betty R. Jackson, and Michael McKee, 1992. "Institutional Uncertainty and Taxpayer Compliance." The American Economic Review 82 (4), 1018-1026.

Alm, James, Betty R. Jackson, and Michael McKee, 1993. "Fiscal Exchange, Collective Decision Institutions, and Tax Compliance." Journal of Economic Behavior and Organization 22 (4), 285-303.

Alm, James and Sarah Jacobson, 2007. "Using Laboratory Experiments in Public Economics." National Tax Journal 60 (1), 129-152.

Alm, James, Gary H. McClelland, and William D. Schulze, 1991. "Why Do People Pay Taxes?" Journal of Public Economics 48 (1), 21-38.

Alm, James, Gary H. McClelland, and William D. Schulze, 1999. "Changing the Social Norm of Tax Compliance by Voting." Kyklos 52 (2), 141-171.

Alm, James and Michael McKee, 2004. "Tax Compliance as a Coordination Game." Journal of Economic Behavior and Organization 54 (3), 297-312.

Alm, James, Isabel Sanchez, and Ana de Juan, 1995. "Economic and Noneconomic Factors in Tax Compliance." Kyklos 48 (1), 3-18.

Andreoni, James, 1989. "Giving with Impure Altruism: Applications to Charity and Ricardian Equivalence." The Journal of Political Economy 97 (6), 1447-1458.

Andreoni, James, 1990. "Impure Altruism and Donations to Public Goods: A Theory of Warmglow Giving." Economic Journal 100 (401), 464-477.

Andreoni, James, 1995. "Cooperation in Public Goods Experiments: Kindness or Confusion?" The American Economic Review 85 (4), 891-904.

Andreoni, James, Brian Erard and Jonathan Feinstein, 1998. "Tax Compliance." The Journal of Economic Literature 36 (2), 818-860. 
Andreoni, James and John Miller, 2002. "Giving According to GARP: An Experimental Test of the Rationality of Altruism." Econometrica 70 (2), 737-753.

Angner, Erik and George Loewenstein, 2010. "Behavioral Economics." In Uskali Mäki (ed.), Handbook of the Philosophy of Science, Volume 13, 67-101. Elsevier, Amsterdam, The Netherlands.

Ariely, Dan, 2008. Predictably Irrational The Hidden Forces That Shape Our Decisions. Harper Collins, New York, NY.

Baron, Jonathan and Edward J. McCaffery, 2003. "The Humpty Dumpty Blues: Disaggregation Bias in the Evaluation of Tax Systems." Organization Behavior and Human Decision Processes 91 (2), 230-242.

Bayer, Patrick J., B. Douglas Bernheim, and John Karl Scholz, 2009. "The Effects of Financial Education in the Workplace: Evidence from a Survey of Employers." Economic Inquiry 47 (4), 605-624.

Beck, Paul, Jon Davis, and Woon-Oh Jung, 1991. "Uncertainty and Taxpayer Aggressiveness: Experimental Evidence." The Accounting Review 66 (3), 535-558.

Becker, Gary S., 1962. "Irrational Behavior and Economic Theory." The Journal of Political Economy 70 (1), 1-13.

Becker, Gary S., 1974. "A Theory of Social Interactions." The Journal of Political Economy 82 (6), 1063-1093.

Bernasconi, Michele and Alberto Zanardi, 2004. "Tax Evasion, Tax Rates, and Reference Dependence." FinanzArchiv 60 (3), 422-445.

Bettinger, Eric, J. Bridget Terry Long, Philip Oreopoulos, and Lisa Sanbonmatsu, 2009. "The Role of Simplification and Information in College Decisions: Results from the FAFSA Experiment.” NBER Working Paper 15361, National Bureau of Economic Research, Cambridge, MA.

Blumkin,Tomer, Bradley J. Ruffle, and Yosef Ganun, 2008. "Are Income and Consumption Taxes Ever Really Equivalent? Evidence from a Real-effort Experiment with Real Goods." CESifo Working Paper No. 2194, University of Munich, Munich, Germany.

Bolton, Gary E. and Axel Ockenfels, 2000. "ERC: A Theory of Equity, Reciprocity and Competition." The American Economic Review 90 (1), 166-193.

Borck, Rainald, Dirk Engelmann, Weiland Müller, and Hans T. Normann, 2002. "Tax Liabilityside Equivalence in Experimental Posted-offer Markets." Southern Economic Journa/ 68 (3), 672-682.

Boulding, Kenneth E., 1958. “Contemporary Economic Research”. In Donald P. Ray (ed.), Trends in Social Science, 9-26. Philosophical Library, New York, NY.

Camerer, Colin F. and George F. Loewenstein, 2004. "Behavioral Economics: Past, Present and Future." In Colin F. Camerer, George F. Loewenstein, and Matthew Rabin (eds.), Advances in Behavioral Economics, 1-61. Russell Sage Foundation and Princeton University Press, Princeton, NJ.

Chetty, Raj, Adam Looney, and Kory Kroft, 2009. "Salience and Taxation: Theory and Evidence." The American Economic Review 99 (4), 145-1177.

Cox, James C. and Vjollca Sadiraj, 2006. "Small- and Large-stakes Risk Aversion: Implications of Concavity Calibration for Decision Theory." Games and Economic Behavior 56 (1), 45-60.

Cox, James C. and Vjollca Sadiraj, 2007. "On Modeling Voluntary Contributions to Public Goods." Public Finance Review 35 (2), 311-332. 
Davis, Douglas D. and Charles A. Holt, 1993. Experimental Economics. Princeton University Press, Princeton, NJ.

DellaVigna, Stefano, 2009. "Psychology and Economics: Evidence from the Field." The Journal of Economic Literature 47 (2), 315-372.

de Bartolome, Charles A. M., 1995. "Which Tax Rate Do People Use: Average or Marginal?" Journal of Public Economics 56 (1), 79-96.

Dhami, Sanjit and Ali al-Nowaihi, 2007. "Why Do People Pay Taxes? Prospect Theory versus Expected Utility Theory." Journal of Economic Behavior and Organization 64 (1), 171192.

Dynarski, Susan and Judith Scott-Clayton, 2006. "The Cost of Complexity in Federal Student Aid." National Tax Journal 59 (2), 319-356.

Elster, Jon, 1989. "Social Norms and Economic Theory." The Journal of Economic Perspectives 3 (4), 99-117.

Fehr, Ernst and Klaus M. Schmidt, 1999. "A Theory of Fairness, Competition, and Cooperation." The Quarterly Journal of Economics 114 (3), 817-868.

Finkelstein, Amy, 2009. "EZ Tax: Tax Salience and Tax Rates." The Quarterly Journal of Economics 124 (3), 969-1010.

Frey, Bruno S., 1992. "Tertium Datur: Pricing, Regulating, and Intrinsic Motivation." Kyklos 45 (2), 161-184.

Friedland, Nehemiah, Schlomo Maital, and Aryen Rutenberg, 1978. "A Simulation Study of Income Tax Evasion." Journal of Public Economics 10 (1), 107-116.

Friedland, Nehemiah. "A Note on Tax Evasion as a Function of the Quality of Information about the Credibility of Threatened Fines: Some Preliminary Research." Journal of Applied Social Psychology 12 No. 55 (February 1982): 54-59.

Gërxhani, Klarita and Arthur Schram, 2006. "Tax Evasion and Income Source: A Comparative Experimental Study." Journal of Economic Psychology 27 (3), 402-422.

Glaeser, Edward L., 2004. "Psychology and the Market." The American Economic Review Papers and Proceedings 94 (2), 408-413.

Glaeser, Edward L., 2006. "Paternalism and Psychology." The University of Chicago Law Review 73 (1), 133-156.

Gordon, James P.F., 1989. "Individual Morality and Reputation Costs as Deterrents to Tax Evasion." European Economic Review 33 (4), 797-805.

Kachelmeier, Steven J., Stephen T. Limberg, and Michael S. Schadewald, 1994. "Experimental Evidence of Market Reactions to New Consumption Taxes." Contemporary Accounting Research 10 (2), 505-545.

Kahneman, Daniel and Amos Tversky, 1979. "Prospect Theory: An Analysis of Decision under Risk.” Econometrica 47 (2), 263-292.

Kagel, John H. and Alvin E. Roth (eds.), 1995. The Handbook of Experimental Economics. Princeton University Press, Princeton, NJ.

Kerschbamer, Rudolf and Georg Kirchsteiger, 2000. "Theoretically Robust but Empirically Invalid? An Experimental Investigation into Tax Equivalence." Economic Theory 16 (3), 719-734.

Kirchler, Eric, 2007. The Economic Psychology of Taxation. Cambridge University Press, Cambridge, UK. 
Kirchler, Eric, Erik Hoelzl, and Ingrid Wahl, 2008. "Enforced Versus Voluntary Tax Compliance: The 'Slippery Slope' Framework.” Journal of Economic Psychology 29 (2), 210-225.

Kling, Jeffrey R., Sendhil Mullainathan, Eldar Shafer, Lee Vermeulen, and Marian V. Wrobel, 2009. "Misperception in Choosing Medicare Drug Plans", Harvard University Working Paper, Cambridge, MA.

Laibson, David I., Andrea Repetto, and Jeremy Tobacman, 1998. "Self-Control and Saving for Retirement." Brookings Papers on Economic Activity 1998 (1), 91-172.

Leamer, Edward E., 1983. "Let's Take the Con out of Econometrics". The American Economic Review 73 (1), 31-43.

Levitt, Steven D. and John A. List, 2007. "What Do Laboratory Experiments Measuring Social Preferences Reveal About the Real World?" The Journal of Economic Perspectives 21 (2), 153-174.

Ledyard, John O., 1995. "Public Goods: A Survey of Experimental Research.” In John H. Kagel and Alvin E. Roth (eds.), The Handbook of Experimental Economics, 111-194. Princeton University Press, Princeton, NJ.

Machina, Mark J., 1987. "Choice under Uncertainty: Problems Solved and Unsolved." The Journal of Economic Perspectives 1 (1), 121-154.

Madrian, Brigitte C. and Dennis F. Shea, 2001. "The Power of Suggestion: Inertia in 401(k) Participation and Savings Behavior." The Quarterly Journal of Economics 116 (4), $1149-1187$.

McCaffery, Edward J. and Joel Slemrod (eds.), 2006. Behavioral Public Finance. Russell Sage Foundation, New York, NY.

Myles, Gareth D. and Robin A. Naylor, 1996. "A Model of Tax Evasion with Group Conformity and Social Customs." European Journal of Political Economy 12 (1), 49-66.

Palfrey, Thomas R., 2006. "Laboratory Experiments in Political Economy." In Barry Weingast and Donald Wittman (eds.), Handbook of Political Economy, 941-963. Oxford University Press, Oxford, UK.

Plott, Charles R., 1987. "Dimensions of Parallelism: Some Policy Applications of Experimental Methods." In Alvin E. Roth (ed.), Laboratory Experimentation in Economics: Six Points of View, 193-229. Cambridge University Press, New York, NY.

Pommerehne, Werner W., Albert Hart, and Bruno S. Frey, 1994. "Tax Morale, Tax Evasion, and the Choice of Policy Instruments in Political Systems.” Public Finance 49 (Supplement), 52-69.

Quirmbach, Herman C., Charles W. Swenson, and Cynthia C. Vines, 1996. "An Experimental Examination of General Equilibrium Tax Incidence." Journal of Public Economics 61 (3), 337-358.

Rabin, Mathew, 2000. "Risk Aversion and Expected Utility Theory: A Calibration Theorem." Econometrica 68 (4), 1281-1292.

Riedl, Arno and Frans van Winden, 2007. "An Experimental Investigation of Wage Taxation and Unemployment in Closed and Open Economies." European Economic Review 51 (4), 871-900.

Roth, Alvin E., 1987. "Laboratory Experimentation in Economics.” In Truman Bewley (ed.), Advances in Economic Theory, Fifth World Congress, 269-299. Cambridge University Press, Cambridge, UK. 
Ruffle, Bradley, 2005. "Tax and Subsidy Incidence Equivalence Theories: Experimental Evidence from Competitive Markets." Journal of Public Economics 89 (8), 1519-1542.

Sausgruber, Rupert and Jean-Robert Tyran, 2005. "Testing the Mill Hypothesis of Fiscal Illusion." Public Choice 122 (1-2), 39-68.

Sillamaa, Mary-Anne, 1999a. "How Work Effort Responds to Wage Taxation: An Experimental Test of a Zero Top Marginal Tax Rate." Journal of Public Economics 73 (1), 125-134.

Sillamaa, Mary-Anne, 1999b. "How Work Effort Responds to Wage Taxation: A Non-Linear versus Linear Tax Experiment." Journal of Economic Behavior and Organization 39 (2), 219-233.

Slemrod, Joel and Shlomo Yitzhaki, 2002. "Tax Avoidance, Evasion, and Administration." In Alan J. Auerbach and Martin Feldstein (eds.), Handbook of Public Economics, 14231470. Elsevier, Amsterdam, London, and New York.

Smith, Vernon, 1976. "Experimental Economics: Induced Value Theory." The American Economic Review Papers and Proceedings 66 (2), 274-279.

Smith, Vernon, 1982. "Microeconomic Systems as an Experimental Science." The American Economic Review 72 (5), 923-955.

Spicer, Michael W. and Lee A. Becker, 1980. "Fiscal Inequity and Tax Evasion: An Experimental Approach." National Tax Journa/ 33 (2), 171-175.

Spicer, Michael W. and Rodney E. Hero, 1985. "Tax Evasion and Heuristics: A Research Note." Journal of Public Economics 26 (2), 263-267.

Spicer, Michael W. and J. Everett Thomas, 1982. "Audit Probabilities and the Tax Evasion Decision: An Experimental Approach." Journal of Economic Psychology 2 (3), 241-245.

Sutter, Matthias and Hannelore Weck-Hannemann. "Taxation and the Veil of Ignorance: A Real Effort Experiment on the Laffer Curve." Public Choice 115 (1-2), 217-240.

Swenson, Charles, 1988. "Taxpayer Behavior in Response to Taxation: An Experimental Analysis." Journal of Accounting and Public Policy 7 (1), 1-28.

Thaler, Richard H. and Cass R. Sunstein, 2008. Nudge - Improving Decisions about Health, Wealth, and Happiness. Yale University Press. New Haven, CN.

Thaler, Richard H. and Shlomo Benartzi, 2004. "Save More Tomorrow: Using Behavioral Economics to Increase Employee Saving." The Journal of Political Economy 112 (S1), S164-S-187.

Torgler, Benno, 2002. "Speaking to Theorists and Searching for Facts: Tax Morale and Tax Compliance in Experiments." Journal of Economic Surveys 16 (5), 657-683.

Torgler, Benno, 2003. "Beyond Punishment: A Tax Compliance Experiment with Taxpayers in Costa Rica." Revista de Análisis Económico 18 (1): 27-56.

Webley, Paul, Henry S. J. Robben, Henk Elffers, and Dick J. Hessing, 1991. Tax Evasion: An Experimental Approach, European Monographs on Social Psychology. Cambridge University Press, Cambridge, UK.

Wilkinson, Nick. 2007. An Introduction to Behavioral Economics A Guide for Students. Palgrave Macmillan, New York, NY.

Yaniv, Gideon, 1999. "Tax Compliance and Advanced Tax Payments: A Prospect Theory Analysis." National Tax Journal 52 (4), 753-764. 